\title{
1. Technology and innovation policy: setting the stage
}

\section{KEY TERMS: IT DEPENDS TO WHOM YOU TALK}

As the title suggests, this book is about technology policy and innovation policy. We will discuss throughout this book that these two areas of policy emphasis are related and that they deserve to be presented separately as well as relatedly because the focus of each policy area is distinct. The difference between the focus of technology policy and innovation policy can simply be illustrated through definitions of the terms technology and innovation.

We emphasize the difference between the definitions of the terms technology and innovation in this introductory chapter because many policy makers, as reflected through their own statements and organizational reports as noted below, frequently subsume technology policy (often without mentioning it by name) under the rubric of innovation policy. This agglomeration may in fact be a valid supposition for a successful technology policy, but not all technology policies fulfill their purposes. Also, we think this agglomeration of technology policy under the rubric of innovation policy masks not only many subtle differences between what a technology is and what an innovation is, but also it masks important differences between the purposes of a technology policy and the purposes of an innovation policy as well as the time element between the two. In addition to policy makers, many academics have also looked at technology policy and innovation policy, with technology policy similarly subsumed under innovation policy, through the lens of national innovation systems, triple/quadruple helix frameworks, and innovation/entrepreneurial ecosystems.

We present definitions of the two terms technology and innovation, as well as other key terms, in this chapter as a starting point for the topics discussed in the chapters that follow. As we illustrate below, there is not a uniform definition of the key terms relevant to the topics presented in this book. This is the case within the academic literature as well as within the policy literature, although the definitions that are presented with reference to these literatures are generally similar. ${ }^{1}$ We devote space here, at the beginning of this book, to several key terms not only for clarity purposes but also to emphasize the lens 
through which we view technology policy and innovation policy. Our point of emphasis is that technology policy and innovation policy refer to different stages in the so-called process of lab to market, to borrow a phrase from the topical policy vernacular.

Our starting point is to define four fundamental terms: science, technology, innovation, and policy. Our working definitions of these key terms are as follows:

- Science - the search for new knowledge; the search is based on observed facts and truths; science begins with known starting conditions and searches for unknown end results.

- Technology - the application of new knowledge, learned through science, to some practical problem.

- Innovation - technology put into use or commercialized.

- Policy - a course of action adopted and pursued by an organization, and herein the organization is assumed to be in the public sector and it is referred to generically as the government.

In our view, what follows from these four definitions is that the term technology policy refers to policy to enhance the application of new knowledge, which often occurs within a research and development (R\&D) laboratory (our emphasis), and the term innovation policy refers to policy to enhance the commercialization of a resulting technology (if there is one), and that commercialization occurs in the market (our emphasis). Thus, our emphasis is on the use of the phrase lab to market. More formally, the terms of relevance are:

- Technology policy - policy to enhance, in a laboratory, the application of new knowledge, learned through science, to some known problem (science is the search for new knowledge; the search is based on observed facts and truths; science begins with known starting conditions and searches for unknown end results). ${ }^{2}$

- Innovation policy - policy to enhance the commercialization of a technology in the market.

The above definitions are collectively presented in Table 1.1 for ease of comparison and reference. 
Table $1.1 \quad$ Definitions of key terms

\begin{tabular}{|c|c|}
\hline Key Term & Definition \\
\hline Science & $\begin{array}{l}\text { The search for new knowledge; the search is based on observed facts and truths; } \\
\text { science begins with known starting conditions and searches for unknown end results. }\end{array}$ \\
\hline Technology & $\begin{array}{l}\text { The application of new knowledge, learned through science, to some practical } \\
\text { problem. }\end{array}$ \\
\hline Innovation & Technology put into use or commercialized. \\
\hline Policy & $\begin{array}{l}\text { A course of action adopted and pursued by an organization, and herein the } \\
\text { organization is assumed to be in the public sector and it is referred to generically as } \\
\text { the government. }\end{array}$ \\
\hline Technology policy & $\begin{array}{l}\text { A policy to enhance, in a laboratory, the application of new knowledge, learned } \\
\text { through science, to some known problem (science is the search for new knowledge; } \\
\text { the search is based on observed facts and truths; science begins with known starting } \\
\text { conditions and searches for unknown end results). }\end{array}$ \\
\hline Innovation policy & A policy to enhance the commercialization of a technology in the market. \\
\hline
\end{tabular}

Source: Prepared by the authors.

We are certainly not the first researchers to offer definitions of the terms technology and technology policy or of the terms innovation and innovation policy, either with respect to the activities and policy actions of one country's firms or government or of the firms and governments in a comparative group of countries. However, as we point out below, there are a number of notable policy documents that proport to advance global innovation policies; however, these documents collectively subsume the concepts of technology and technology policy within the discussion of an innovation and an innovation policy, although some of these documents even fail to define what is meant by the term innovation. ${ }^{3}$

Examples of notable policy documents in which the term innovation has been defined include the Global Trade and Innovation Policy Alliance's National Innovation Policies: What Countries Do Best and How They Can Improve. Therein it is written that (GTIPA, 2019, p. 2): ${ }^{4}$

... innovation is the improvement of existing, or the creation of entirely new, products, processes, services, and business or organizational models. Put simply, innovation is about the creation of new value for the world.

And it follows from this definition of an innovation that an innovation policy is a governmental effort aimed at the improvement of existing - or the creation of entirely new - products, processes, services, and business or organizational models. 
In a Nesta report, prepared by Stanley, Glennie, and Gabriel, How Inclusive Is Innovation Policy? Insights from an International Comparison, the following is written about innovation (Nesta, 2008, p. 6, emphasis in original):

[W]e define innovation broadly as new ideas that are put into practice and create some kind of value ... then innovation policy can be characterized as all combined actions that are undertaken by public organizations that influence the innovation process.

The Organisation for Economic Co-operation and Development (OECD), in its report OECD Innovation Strategy 2015: An Agenda for Policy Action, writes (OECD, 2015a, p. 2):

[Innovation] involves the creation and diffusion of new products, processes and methods.

The OECD also uses this same definition in its report The Innovation Imperative Contributing to Productivity, Growth and Well-Being (OECD, $2015 b$ ). Elsewhere, the OECD offers, for data collection purposes, a more complete definition of the term innovation. According to the OECD report The Measurement of Scientific, Technological and Innovation Activities: Oslo Manual 2018 GUIDELINES FOR COLLECTING, REPORTING AND USING DATA ON INNOVATION (OECD, 2018b, p. 20):

An innovation is a new or improved product or process (or combination thereof) that differs significantly from the unit's previous products or processes and that has been made available to potential users (product) or brought into use by the unit (process).

The European Commission (EC, 2020) interprets the term innovation in the following way:

... to accelerate the modernization of the EU industry, the update of products and service innovation, use of innovative manufacturing technologies and the introduction of new business models is necessary. The [European] Commission develops policies that help speed up the broad commercialisation of innovation and engages in many activities that support innovation in the EU [European Union].

Innovation policy within the EU has been enshrined into law through the Treaty on the Functioning of the European Union Article 173.5 Therein it is stated that:

The Union and the Member States shall ensure that the conditions necessary for the competitiveness of the Union's industry exist.

1. For that purpose, in accordance with a system of open and competitive markets, their action shall be aimed at: 
- speeding up the adjustment of industry to structural changes,

- encouraging an environment favourable to initiatives and to the development of undertakings throughout the Union, particularly small and medium-sized undertakings,

- encouraging an environment favourable to cooperation between undertakings,

- fostering better exploitation of the industrial potential of policies of innovation, research and technological development.

2. The Member States shall consult each other in liaison with the Commission and, where necessary, shall coordinate their action. The Commission may take any useful initiative to promote such coordination, in particular initiatives aiming at the establishment of guidelines and indicators, the organisation of exchange of best practice, and the preparation of the necessary elements for periodic monitoring and evaluation. The European Parliament shall be kept fully informed.

3. The Union shall contribute to the achievement of the objectives set out in paragraph 1 through the policies and activities it pursues under other provisions of the Treaties. The European Parliament and the Council, acting in accordance with the ordinary legislative procedure and after consulting the Economic and Social Committee, may decide on specific measures in support of action taken in the Member States to achieve the objectives set out in paragraph 1, excluding any harmonisation of the laws and regulations of the Member States.

The European Innovation Scorecard and Regional Innovation Scorecard are both mechanisms that are used to evaluate innovation policy performance across Member States in the EU. The EU Framework Programmes, European Regional Development Fund (ERDF), and different financial instruments are policy approaches that the EU has used to implement innovation policy across the Member States. For example, the current EU Framework Programme, Horizon Europe 2021 to 2027, further affirms the continued objective "to support the whole R\&I [research and innovation] cycle in an integrated manner."

With respect to research and technology development, the Treaty on the Function of the European Union devotes Articles 179 to 190 to outlining the legal basis of the EU's approach in this regard. Article 179 states;

1. The Union shall have the objective so strengthening its scientific and technological bases by achieving a European research area in which researchers, scientific knowledge and technology circulate freely, and encouraging it to become more competitive, including in its industry, while promoting all the research activities deemed necessary by virtue of other Chapters of Treaties.

2. For this purpose the Union shall, throughout the Union, encourage undertakings, including small and medium-sized undertakings, research centres and universities in their research and technological development activities of high quality; it shall support their efforts to cooperate with one another, aiming, notably, at permitting researchers to cooperate freely across borders and at enabling undertakings to exploit the internal market potential to the full, in particular through 
the opening-up of national public contracts, the definition of common standards the removal of legal and fiscal obstacles to that cooperation.

3. All Union activities under the Treaties in the area of research and technological development including demonstration projects, shall be decided on and implemented in accordance with the provisions of this Title.

Article 180 of the Treaty on the Function of the European Union emphasizes complementary activities across Member States in the development of research progress:

In pursuing these objectives, the Union shall carry out the following activities, complementing the activities carried out in the Member States:

(a) implementation of research, technological development and demonstration programmes, by promoting cooperation with and between undertakings, research centres and universities;

(b) promotion of cooperation in the field of Union research, technological development and demonstration with third world countries and international organisations;

(c) dissemination and optimization of the results of activities in Union research, technological development and demonstration;

(d) stimulation of the training and mobility of researchers in the Union.

These two articles, Article 179 and Article 180, in the Treaty on the Function of the European Union provide the legal basis that has led to the creation of the European Framework Programmes, the European Research Area Net (created in 2002), and the European Institute of Innovation Technology (created in 2008).

With these definitions and/or key terms in mind, and we emphasize again that technology and technology policy are not explicit building blocks for innovation and innovation policy in the text of the sample of definitions from the policy reports quoted above, a logical more general question to ask is: Why is technology policy important, and: Why is innovation policy important?

Our response to these two questions is not independent from how we approach the actions that fall under the rubrics of technology policy and innovation policy; that is, our response to these two questions reflects the lens through which we wrote this book.

One might choose to study technology policy and innovation policy in somewhat structured terms. Such an approach to the study of technology policy and innovation policy might take the following contextual form. One would learn under this structure that policy A was adopted in year $\mathrm{x}$ for the purpose of ...; policy B was adopted in year $y$ for the purpose of .... The importance of studying technology policy and innovation policy in this manner is to characterize the context in which economic growth (discussed below) occurs. 
However, if one chooses to study technology policy and innovation policy from an assessment or evaluation perspective, one might learn to associate policy A with a unique performance dimension associated with economic growth, and to associate policy B with another performance dimension associated with economic growth. Thus, a comparison of the impact of policy A with policy B necessitates metrics to quantify dimensions of economic growth (see Link, 1993, 2006).

Many studies have demonstrated that technology policy does have an impact on economic performance and thus on economic growth (see Dasgupta and Stoneman, 2005; Metcalfe, 1994). Technology policy also has an impact on the performance of firms (see Zahra and Covin, 1993). More recently, a vein in the academic literature has begun to explore the societal impacts of technology policy by researchers from a number of different disciplines (see Fini et al., 2018; Fisher, 2005; Schillo and Kinder, 2017).

In designing such technology policies, Mowery (1983), as an example, argued the need for policy makers to focus on both the supply of research and development (R\&D) and its allocation among participants during the technology development process. Similarly, studies have also examined the impact of innovation policy at an economic level (see Asheim, 2019; Fagerberg, 2017; Flanagan et al., 2011; Kuhlmann, 2001; Mazzucato, 2017), at a firm level (see Becker, 2019; Tang et al., 2018; Wadho and Chaudhry, 2018), and at the level of society as a whole (see Esmaeilpoorarabi et al., 2018; Mazzucato et al., 2020).

Moreover, the evolution to innovation policy in some countries has emanated from industrial policy (see Cunningham et al., 2020; Soete, 2007), and this perspective is set against a changing conceptualization of innovation (see Meissner et al., 2017). Researchers have argued, and have supported their arguments with references to empirical studies in the academic literature, that the importance of innovation policy is related to how it focuses on and considers issues such as societal grand challenges (see Coenen et al., 2015; Hayter and Link, 2020), sectoral challenges (see Hall, 2009), as well as the support and enhancement of regional innovation (see Cunningham et al., 2019a).

Over the previous decades, researchers have attempted to conceptualize and evaluate empirically the relationship between technology policies and innovation policies, and the affected parties of individuals, firms, and the public sector or government. Technology and innovation policies are primarily intended to support and advance economic growth that might then result in second order impacts that have net benefits for society and its citizens. Such a conceptualization (see Piazza and Abrahamson, 2020) has evolved considerably over time in part to deal with complex and nuanced policy challenges that policy makers face when crafting and implementing effective technology policies and innovation policies that result in a tangible, if not a transformative, change for 
end users or recipients of such policies. This evolution has also been driven by a number of significant and accelerated changes across different industrial sectors brought about by technological advancements, more effective firm-level knowledge management practices, and firm-level business models of innovation per se and of the management of innovation (see Birkinshaw et al., 2008; Chesbrough, 2010; Darroch, 2005). Such conceptualizations have been formulated on the basis of national innovation systems (see Cunningham and Golden, 2015; Freeman, 2002; Lundvall, 2007), industrial clusters (see Feldman et al., 2005; Green et al., 2001; Iammarino and McCann, 2006), triple helix models (see Leydesdorff and Etzkowitz, 1998: Leydesdorff and Meyer, 2003), quadruple helix models (see Carayannis and Campbell, 2009; Miller et al., 2016), entrepreneurial ecosystems (see Audretsch et al., 2019a; Cantner et al., 2020; Cunningham et al., 2019b; Spigel, 2017; Spigel and Harrison, 2018), and innovation ecosystems (see Autio and Thomas, 2014; Oh et al., 2016; Walrave et al., 2018). Such conceptualizations are generally temporal in nature because the policy challenges that they are attempting to address require an approach that results not only in the advancement of knowledge, but also in a message that is appealing and relevant to policy makers and their constituents.

This book contains elements of many previous approaches to the study of technology policy and innovation policy. We emphasize in this book, where appropriate, the context in which a technology policy or an innovation policy is promulgated. We also emphasize, where appropriate, assessment and evaluation perspectives related to a technology policy or an innovation policy.

\section{THE IMPORTANCE OF INNOVATION POLICY}

Staying within the context of the policy references quoted just above, and keeping in mind that these policy references implicitly as well as explicitly subsume technology policy under the rubric of innovation policy (although that pedagogical masking was not explicitly stated within the context of the quoted phrases above), we note in this section of this chapter the economic growth implications that are attributable to innovation policies.

The Global Trade and Innovation Policy Alliance, in its National Innovation Policies: What Countries Do Best and How They Can Improve, wrote (GTIPA, 2019, p. 2):

Innovation matters because it's the foundational source of long-term global economic growth and improvements in quality of life and standards of living. 
The OECD wrote in The Innovation Imperative Contributing to Productivity, Growth and Well-Being (2015b, p. 17):

A key interest of policy makers in innovation has long been around its potential contribution to economic growth.

Finally, the U.S. National Research Council (NRC) wrote in its report Capturing Change in Science, Technology, and Innovation: Improving Indicators to Inform Policy (NRC, 2014, p. 44):

... it is clear that as a national goal, policies that encourage bringing more innovations to market are useful if they generate economic growth and jobs and improve the nation's competitiveness.

Our approach to presenting an international perspective on technology policy and innovation policy is guided in part by (or should we say, limited in part by) our experiences and relative familiarity with U.K. and U.S. technology policy and innovation policy. Accordingly, we ask: What was the genesis of emphasis on innovation policy which led to the association between innovation and economic growth? And our contemporary answer relates to the productivity slowdown that was pervasive in most industrialized nations beginning in the early 1970s.

Our empirical illustrations related to technology policy and innovation policy focus in detail on the U.K. and the U.S. experiences, and to a lesser extent on the experiences of other international countries for which data are available. Of course, policies in all countries merit an in-depth study. In fact, a number of detailed descriptive studies of innovation policies across OECD member companies have been prepared. Looking ahead, in Chapter 7 we will offer generalizations from these OECD studies as an effort toward a more encompassing and comprehensive international study of national innovation policies. ${ }^{8}$

\section{THE PRODUCTIVITY SLOWDOWN: AN INTERNATIONAL GLIMPSE}

From an international perspective, Figures 1.1, 1.2, and 1.3 show the annual percentage change in Gross Domestic Product (GDP) per capita, in constant prices, in the United Kingdom, the United States, and the G7 countries (Canada, France, Germany, Italy, Japan, the United Kingdom, and the United States). ${ }^{9}$ This index, GDP per capita, measures a dimension of labor productivity over the years 1971 through $2019 .{ }^{10}$ Ideally, we would like to have illustrated total factor productivity (also referred to as multi-factor productivity) 
over time, but the OECD data on that index began only in 1985 (a few years after the productivity slowdown, discussed below, had ended). ${ }^{11}$

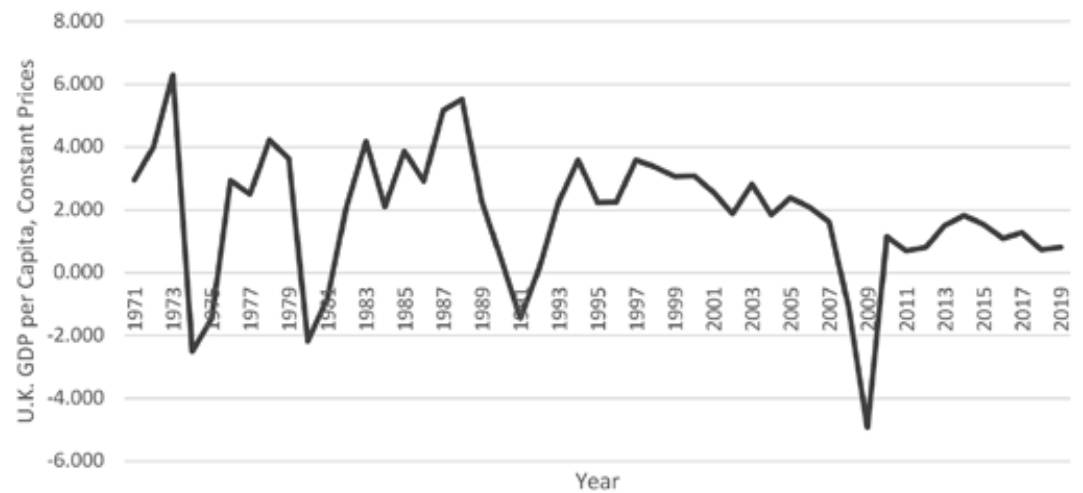

Source: https://stats.oecd.org/Index.aspx?DataSetCode=MSTI_PUB (accessed September 16, 2020).

Figure 1.1 Annual percentage change in U.K. Gross Domestic Product per capita in constant prices

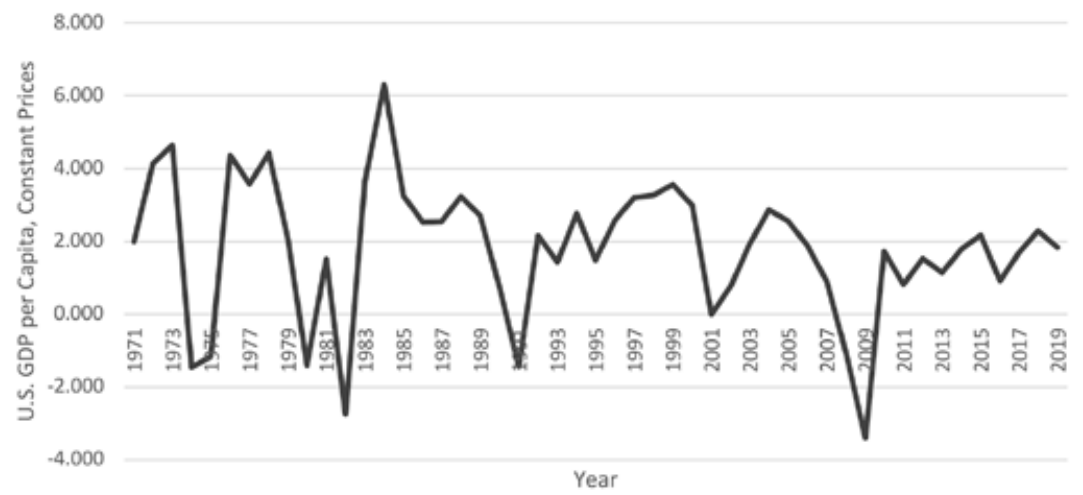

Source: https://stats.oecd.org/Index.aspx?DataSetCode=MSTI_PUB (accessed September 16, 2020).

Figure 1.2 Annual percentage change in U.S. Gross Domestic Product per capita in constant prices 


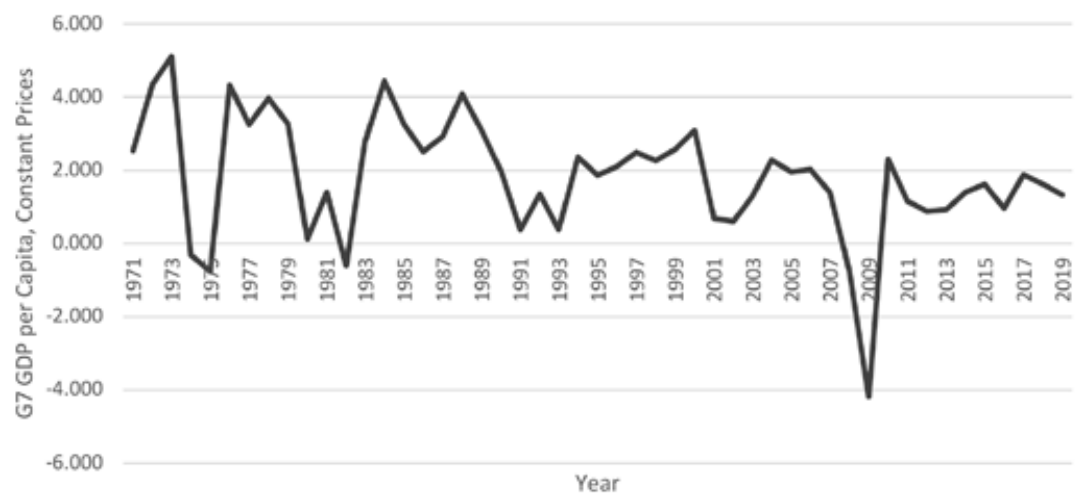

Source: https://stats.oecd.org/Index.aspx?DataSetCode=MSTI_PUB (accessed September 16, 2020).

Figure 1.3 Annual percentage change in G7 Gross Domestic Product per capita in constant prices

In the United Kingdom, the United States, and the G7 countries as a group, measured labor productivity declined in the early 1970s and then again in the late 1970s and early 1980s. In fact, the labor productivity declines during these periods are rivaled in the post-World War II period only by the Great Recession of 2007-2009.

Many argue that the initial decline in labor productivity (and multi-factor productivity) was associated with the 1973 oil crisis and the production method adjustments by industry that followed. The subsequent declines have been associated, often in a causal manner, with a decline in investments in $\mathrm{R} \& \mathrm{D}$, and investments in $\mathrm{R} \& \mathrm{D}$ have long been associated with new technologies being developed and then entering the market. Thus, the relevant literatures have focused on variations of the following paradigm:

$$
R \& D \rightarrow \text { technology } \rightarrow \text { innovation } \rightarrow \text { economic growth }
$$

This paradigm has often been referred to as the linear model, and it is generally referenced to Bush's Science - the Endless Frontier (1945), more in terms of conceptualization than explicitly by name. ${ }^{12}$ The innovation $\rightarrow$ economic growth portion of this paradigm is perhaps what underlies the arguments posed above about the consequence of innovation policy. However, to the extent that this paradigm has construct validity, it buttresses our argument that the innovation flows from new technology and thus effective technology policy, focused 
on $\mathrm{R} \& \mathrm{D}$ investments, is a relevant prerequisite to consider for the development of innovation policy.

\section{A ROADMAP OF THE CHAPTERS THAT FOLLOW}

In Chapter 2, we focus on technology policies to enhance private-sector R\&D. We first describe private-sector R\&D investments across countries and over time. Then, we ask why a country needs a technology policy to enhance its private-sector's investments in R\&D, and we answer that question in terms of the economics concept of market failure. We focus on both direct and indirect incentives by the government to encourage firms to investment more in R\&D.

Chapter 2 segues to Chapter 3 in which we discuss, in an exploratory manner, the effectiveness of technology policies to enhance private-sector R\&D. In Chapter 3 we offer some descriptive empirical insight into the effectiveness of the two technology policies discussed in Chapter 2: tax incentives and direct subsidies. We also introduce a framework for explaining the role of investments in R\&D and the role of technology policy and innovation policy in the economy as well as the relationship between the two policies.

In Chapter 4, we continue to explore dimensions of the effectiveness of U.S. direct subsidies to R\&D.

In Chapter 5, we discuss the technology policy environment in which private-sector investments in R\&D occur. Key infrastructural elements of that environment are a country's patent system and incentives in place to encourage R\&D collaborations.

In Chapter 6, we discuss technology policies to leverage public-sector R\&D. The policies that we discuss focus on incentives aimed at the public sector's efforts to encourage knowledge transfers from universities and national laboratories to the private sector.

Chapter 7 summarizes key findings from OECD reports on the innovation policies in various countries in an effort to identify common characteristics, and thus to give construct validity to the framework that we developed in the earlier chapters.

Finally, in Chapter 8, we offer concluding observations about technology and innovation policies across countries. We also include in this chapter a discussion of a technology policy ecosystem in which actors play a critical role in the development and implementation of technology policies reflected in the technology policy environment. 


\section{NOTES}

1. As Audretsch et al. (2019b, p. 2) point out, different academic disciplines view the concept of innovation differently. These authors offered the following generalizations. In the field of finance, innovation is viewed in terms of the "allocation by firms of financial resources to innovative activities and the accessing by those firms of funds to finance innovation." In the field of entrepreneurship, innovation is characterized as follows: "Innovation-driven firms and entrepreneurs engage with a variety of knowledge providers (collaborations, spillovers) while also investing in research and development to disrupt the market equilibrium by introducing new ideas, products and services." In the field of management, innovation is viewed in terms of the "access and development of the capacity, skills and resources to identify, pursue and coordinate innovation in processes, products, management and business models." Finally, in the area of marketing, innovation captures the "creation of a steady stream of new products and services that meets the needs of customers." We add to these alternative conceptualizations the economics view that an innovation is defined in terms of a shift in a production function.

2. Our use of the phrase in a laboratory is not intended to dismiss entrepreneurial actions that lead to a new technology. For some entrepreneurs, the appropriate laboratory might be a basement or garage. That said, the technology policies that we discuss in this book are generally aimed at institutions performing R\&D. Accordingly, levels of investments in R\&D are in general the target variable for technology policy.

3. Many researchers point to Schumpeter for a foundational definition of an innovation, but as Hébert and Link (2009) point out, the notion of an innovation traces to scholars much before the time of Schumpeter's writings. That said, it is important to acknowledge Schumpeter's view of innovation because his is the view that arguably is most closely related to entrepreneurial behavior in the modern literature. What follows in the rest of this note is paraphrased text directly from Hébert and Link (2009).

Schumpeter described innovation in terms of new combinations that underlie economic development. These combinations included the following: (1) creation of a new good or new quality of good; (2) creation of a new method of production; (3) the opening of a new market; (4) the capture of a new source of supply; (5) a new organization of industry (e.g., creation or destruction of a monopoly). Over time, these new combinations dissipate, as the new becomes part of the old (i.e., a circular flow). But, this evolution does not change the essence of the entrepreneurial function.

More specifically, Schumpeter defined innovation with reference to a production function, which (Schumpeter, 1939, p. 62) "describes the way in which quantity of product varies if quantities of factors vary. If, instead of quantities of factors, we vary the form of the function, we have an innovation." Note our conceptualization of the economics view of innovation in note 1 above. Regarding the source of innovation, Schumpeter recognized that the knowledge that kindles an innovation need not be new (Schumpeter, 1928, p. 378): "it is not the knowledge that matters, but the successful solution of the task sui generis of putting an untried method into practice - there may be, and often is, no scientific novelty involved at all, and even if it be involved, this does not make any difference to the nature of the process." 
In Schumpeter's theory, successful innovation depends, therefore, on leadership, not intelligence, and it should not be confused with invention. The leadership that constitutes innovation in the Schumpeterian system is not homogeneous. According to Schumpeter (1928, p. 380), different aptitudes for the routine work of "static" management result merely in differential success at what all managers do, whereas different leadership aptitudes mean that "some are able to undertake uncertainties incident to what has not been done before; [indeed] ... to overcome these difficulties incident to change of practice is the function of the entrepreneur."

4. The Global Trade and Innovation Policy Alliance (GTIPA, 2019, p. 1) "is a global network of independent think tanks that are ardent supporters of greater global trade liberalization and integration, deplore trade-distorting 'innovation mercantilist' practices, but yet believe that governments can and should play important and proactive roles in spurring greater innovation and productivity in their enterprises and economies. Member organizations advocate and adhere to research and policy consistent with a core Statement of Shared Principles."

5. See Official Journal of the European Union, Consolidated Version of the Treaty on the Functioning of the European Union at: https://eur-lex.europa.eu/LexUriServ/ LexUriServ.do?uri=CELEX:12012E/TXT:EN:PDF (accessed September 15, 2020).

6. See European Commission (EC, 2018) Proposal for a Regulation of the European Parliament and of the Council Establishing Horizon Europe-the Framework Programme for Research and Innovation. Therein, the EC sets forth its rules for participation and dissemination. See https:/www.europarl.europa.eu/RegData/ docs autres institutions/commission_europeenne/com/2018/0435/COM $\mathrm{COM}(2018) \overline{0} 435$ EN.pdf (accessed September 15, 2020).

7. As Link and Scott (2011) explain, a policy assessment is based primarily on the criterion of effectiveness: Has a policy met its stated goals and objectives? Have its designated outputs been achieved? A policy evaluation is based on the criterion of efficiency: How do the social benefits or outcomes associated with the policy compare to the social costs?

8. See https://www.oecd.org/sti/inno/oecd-reviews-of-innovation-policy.htm (accessed September 16, 2020).

9. The so-called Group of Seven (G7) countries are among the largest and wealthiest countries in the world.

10. We will rely throughout this book on international data primarily from the OECD. The years of available data will vary across the metrics that we consider. In all cases, we will use an appropriate number of years of information to illustrate our policy points.

11. A total factor productivity or multi-factor productivity index is the preferable metric through which to measure aggregate productivity trends at the national level. When available, even for a limited number of years, we will consider multi-factor productivity indices. A primer on the construction of a multi-factor productivity index is at: https://www.bls.gov/mfp/mprtech.htm (accessed September 16, 2020).

12. An excellent discussion of the linear model concept is in Godin (2006). 